\title{
Advantages of pre-fabricated reinforced concrete construction in Iraq
}

\author{
Ivan Abramov ${ }^{1}$, Aleksander Stepanov ${ }^{1}{ }^{2.1}$ and Ibrahim F. Ibrahim ${ }^{1}$ \\ ${ }^{I}$ Moscow State University of Civil Engineering, 26 Yaroslavskoye Shosse, Moscow, Russian \\ Federation
}

\begin{abstract}
With its building infrastructure almost completely destroyed during the military conflict, modern Iraq is facing an urgent need for a number of measures to increase the quality of installation, construction and reconstruction jobs and to reduce timeframes taking into account local and climatic features. To achieve this, the priority task is to develop methods and theoretical recommendations based on the analysis of existing methods for calculating construction timeframes, ones that would most accurately reflect the influence of such factors as cement class, type and an average daily air temperature. The climatic conditions in Iraq impact negatively on the properties of hardened concrete. Specifically, concrete mixture shrinks more rapidly, which entails a change in its physico-mechanical properties and further corrosion of reinforcement bars at joints in monolithic prefabricated housing construction. This paper aims to determine factors that affect construction timeframes and quality for prefabricated reinforced concrete buildings, and to develop a model on the basis of statistical research to determine the concrete hardening time at joints in prefabricated frame housing construction.
\end{abstract}

\section{Keywords:}

Pre-fabricated frame housing construction, grouting of joints, pre-fabricated reinforced concrete structures

\section{Introduction}

Reconstruction and renovation of housing stock is one of the most important tasks on the agenda in a country's housing policy [1]. This article looks into the trends that are currently taking shape as regards to the choice of effective construction technology solutions suitable for house building in Iraq.

Construction technology solutions should be economical, technically feasible and functional.

When studying the available construction solutions or individual structural designs one should choose by comparing their technical parameters to those provided for in local detailed designs.

When comparing the available design options for building structures, the necessary criteria would be: identical purpose, same payload values and project's compliance with current construction design standards. When carrying out a feasibility study of structures, the following array of parameters should be evaluated: cost of manufacture, the amount of capital investment, operating costs, weight, volumes, consumption of basic materials (steel, sawn timber, cement, etc.), installation and labor input. As best practice suggests, a

2.1 Contact the author at: inferno1020@mail.ru 
prerequisite for finding the right design solution for buildings and related structures is a decent feasibility study with due account of all factors affecting the efficiency of solutions $[2,3]$.

One of the main directions is monolithic reinforced concrete construction. Reinforced concrete is, and in the near future will remain, the main type of material used in the construction of buildings and structures of various purposes in Iraq. However, the actual technical and economic parameters are affected by a number of factors considered in this article. The Iraqi climate is diverse with very hot summers and cold winters; temperatures may vary during the day $+\left(50-53^{\circ} \mathrm{C}\right)$ and at night to $-\left(5-8^{\circ} \mathrm{C}\right)$, especially in the north of the country, in the mountainous Iraqi Kurdistan. The large temperature differences increase labor intensity and costs in the process of monolithic housing construction in Iraq.

Performance of construction and installation jobs on site is associated with a number of negative factors [4] that normally affect construction timeframes, the use of construction machinery on the construction site and consumption of construction materials. Consequently, the factors in question drive up significantly the costs of performing the entire range of construction and installation jobs beyond initial projections. Thus, all these factors affecting the quality of the final result during construction can be divided into two groups [5]:

1. negative factors typical of the entire construction and installation period

- construction of facilities on the slopes of mountains with sharply intersected relief with a severe continental climate;

2. negative factors only typical of certain types of construction work at various stages of construction;

- construction of new facilities in cramped conditions: on the premises of the existing enterprises, which entails cramped material storage conditions;

- reconstruction, restoration of facilities after man-caused impacts.

When erecting monolithic reinforced concrete buildings the process of casting a concrete mixture is exposed to one of the above factors, specifically the severe continental climate. As is known, concrete's binding property is the key indicator in monolithic housing construction and, in many respects, it determines its physical and mechanical properties. The rapid gaining of strength at the early stages of concrete hardening leads to the formation of dense shells around new tiny bodies that impede water access to nonhydrated cement grains. At the same time, hydration is a fast process, which limits concrete's strength from growing further. The structure of concrete can also be broken as a result of periodic daily and seasonal changes in air temperature and humidity, which cause compressive and tensile strength as well as the elasticity modulus to grow. Reinforced concrete structures (prefabricated reinforced concrete) after gaining strength (of $85 \%$ and higher) upon being manufactured are less affected by the hot climate and are widely used as an efficient construction technology solution for erecting buildings and structures in Iraq [6,7].

Prefabricated reinforced concrete products are structures or products manufactured at a plant and transported to a construction site for subsequent assembly or installation.

One of the main processes in the construction and assembly work from prefabricated reinforced concrete is filling joints with concrete.

When constructing such joints, a formwork needs to be used for casting concrete and mortar and it should be properly treated to ensure it gains all the properties necessary. The erection technology used in prefabricated reinforced concrete construction, depending on the number and type of elements connected together, connections are divided into joints, fittings and seams. The joining of two structural elements in one place is called a joint; three or more elements are called a fitting (for example, joining a column, crossbar and floor slabs in multi-story frame buildings). A seam is the point of connection (contact) 
between individual structural elements, for example, slabs of coatings and wall panels. Grouting allows not only fixing, but also stabilizing the joints of prefabricated elements, as well as obtaining a spatial rigidity of the entire structure. Stability, design position, reliability and durability of prefabricated structures largely depend on how well the joints of prefabricated elements and structures are grouted [8].

When erecting prefabricated reinforced concrete buildings, grouting of joints is considered an important stage and is recorded in a special joint grouting log.

To make sure that concrete at joints has gained due strength, it needs proper treatment. When work is performed in hot and dry weather, manufacture of concretes should generally use plasticizing and complex additives accelerating the hardening process. One of the important treatment techniques is reducing the amount of water evaporating from concrete's surface, a measure especially relevant in the dry and hot climate of Iraq.

In order to reduce the amount of water evaporating from the surface (the surface of the concrete mixture) the recommendation is to apply additives that are less dense than water and do not dissolve in it forming a thin protective layer on the surface. The use of such additives greatly simplifies treatment of the concrete mixture after casting, reduces labor input and lowers the costs of water so scarcely found in Iraq [9].

Prefabrication companies are rare in this country despite the fact that in 2013 the Iraqi Ministry of Housing and Construction declared that prefabricated system will be the main construction system. The first precast concrete plant was opened recently on April 2014 at Bismayah, Baghdad which mainly produces pre-fabricated reinforced concrete structures[10].

The air temperature in Iraq in summer is $+44^{\circ} \mathrm{C}$ on average [11]. Table 1 shows the study of concrete hardening times for different temperatures and cement classes.

Table No. 1. Concrete hardening times for different temperatures and cement classes.

\begin{tabular}{|l|l|l|l|l|l|}
\hline \multirow{2}{*}{$\begin{array}{l}\text { Type and class of } \\
\text { cement used in the } \\
\text { manufacture of } \\
\text { concrete }\end{array}$} & $\begin{array}{l}\text { Concrete } \\
\text { strength, } \\
\text { of the } \\
\text { design value }\end{array}$ & \multicolumn{4}{|l|}{$\begin{array}{l}\text { Concrete hardening times in days at an } \\
\text { average hardening temperature }\end{array}$} \\
\cline { 3 - 6 } & 25 & 30 & 35 & 44 \\
\hline Portland Cement 22.5 & 50 & 4 & 3 & 2.5 & 2 \\
& 70 & 7 & 6 & 5 & 4.5 \\
& 100 & 16 & 14 & 12 & 11 \\
\hline Portland Cement B & 50 & 3 & 2.5 & 2 & 1.5 \\
32.5 & 70 & 6 & 5 & 4 & 3.5 \\
& 100 & 14 & 12 & 10 & 9 \\
\hline Portland Cement B & 50 & 2 & 1.8 & 1.5 & 1.3 \\
42.5 & 70 & 3 & 2.5 & 2 & 1.8 \\
& 100 & 10 & 8 & 6 & 5 \\
\hline High Early Strength & 50 & 1.5 & 1.2 & 1 & 0.8 \\
Portland cement & 70 & 2.5 & 2 & 1.5 & 1 \\
& 100 & 8 & 6 & 4 & 3 \\
\hline
\end{tabular}




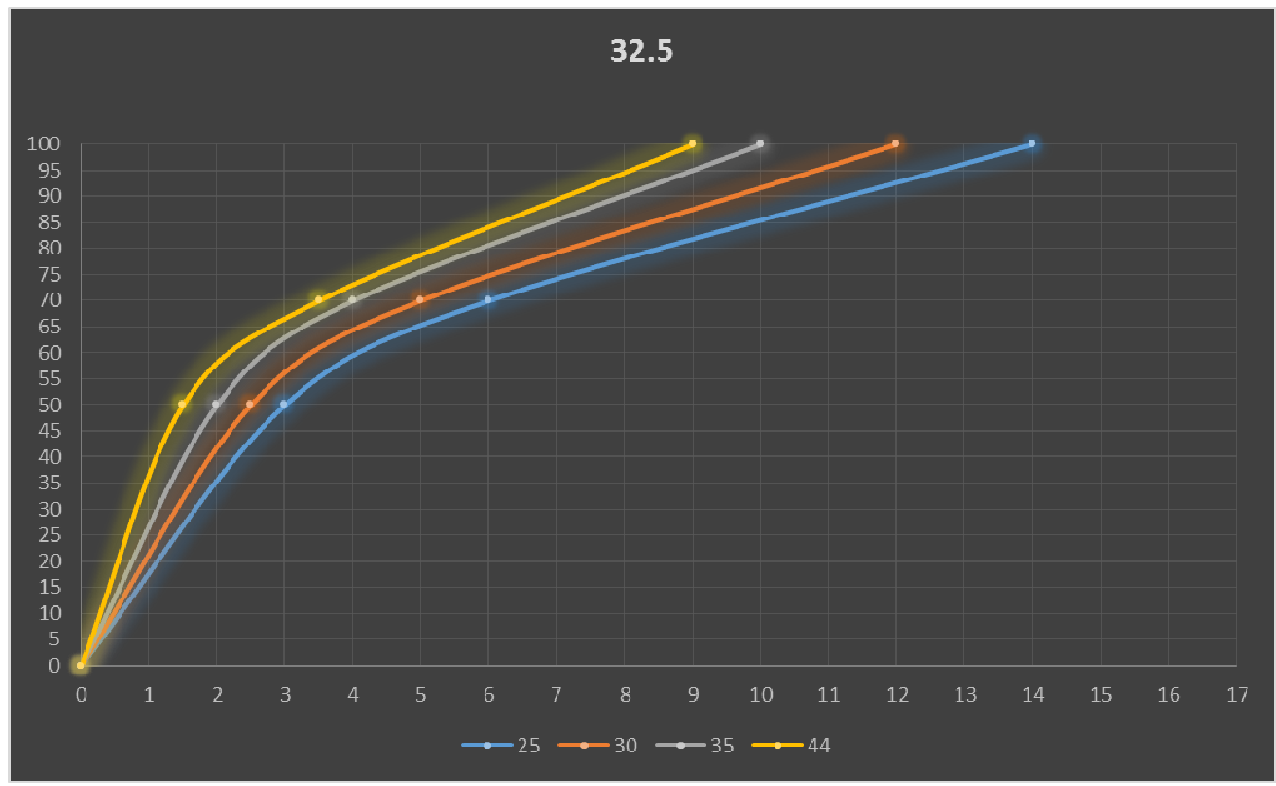

Fig.1 . Dependence of concrete's design strength gaining time on the cement class and air temperature

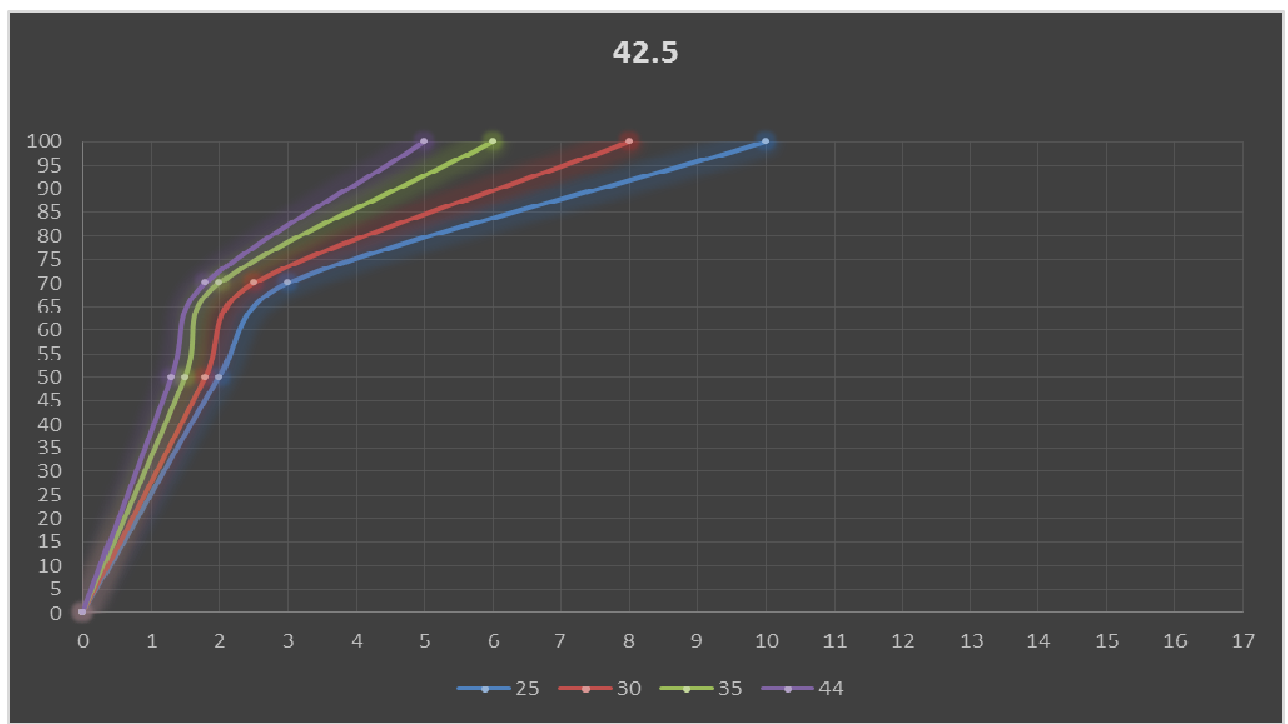

Fig.2 . Dependence of concrete's design strength gaining time on the cement class and air temperature 


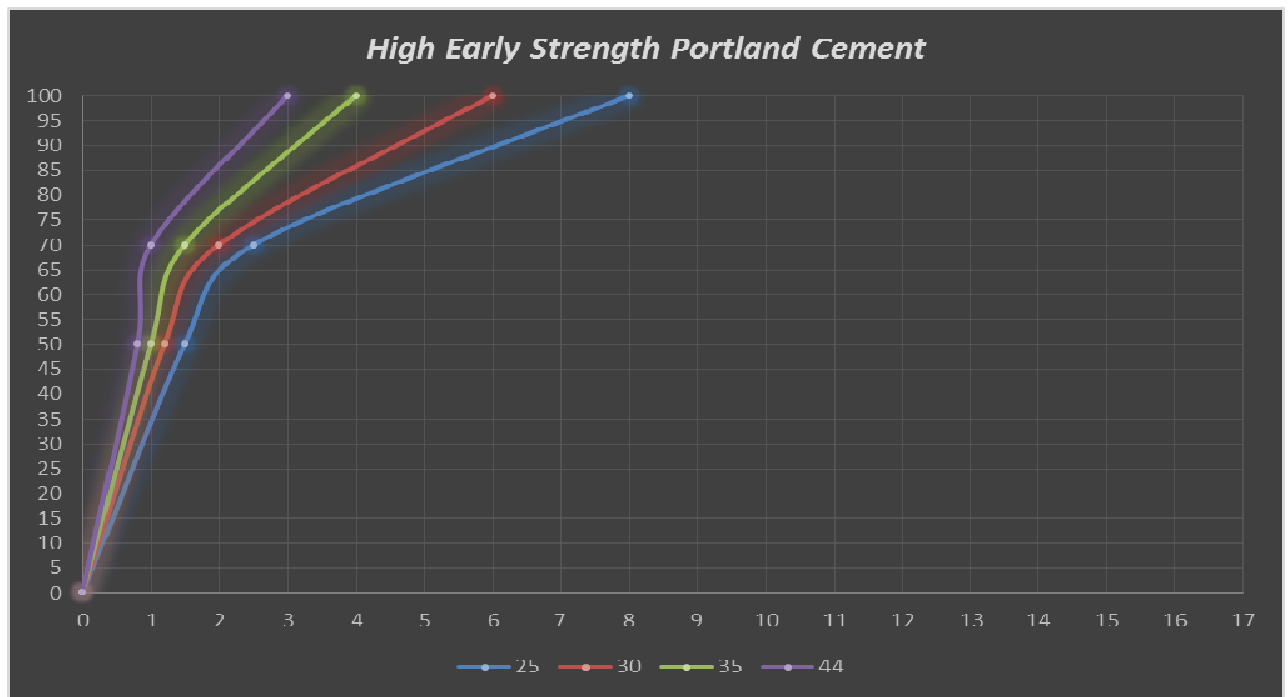

Fig.3 . Dependence of concrete's design strength gaining time on the cement class and air temperature.

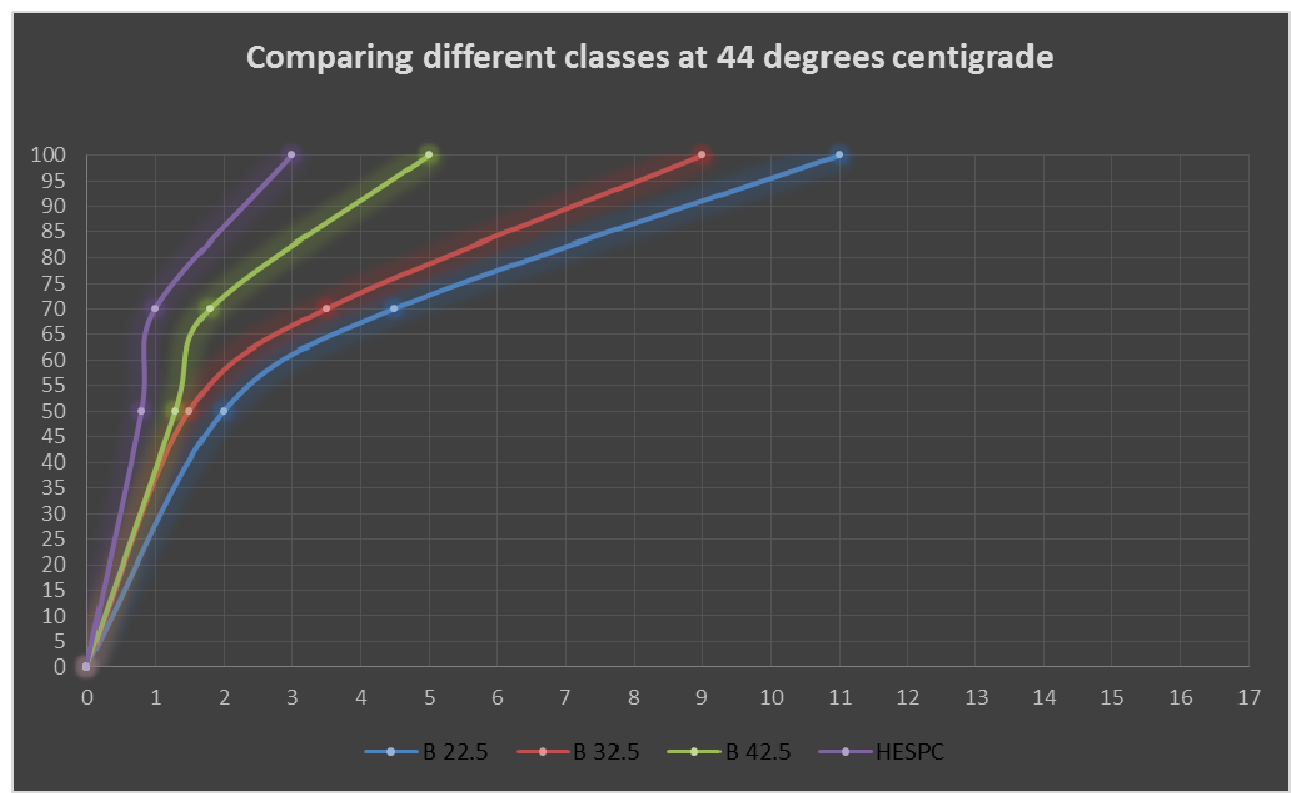

Fig.4. Linear description of concrete gaining the design strength compared across different cement classes

\section{Conclusion}

The comparative data suggests that, at a temperature of $+44 \mathrm{C}^{\circ}$, the type of concrete that gains strength fastest (three days) is the one using High Early Strength Portland Cement. Concrete using Grade 42.5 Portland Cement gains the design strength of $100 \%$ on the $5^{\text {th }}$ day.

Concrete with the use of Class 32.5 Portland Cement gains maximum design strength on the $9^{\text {th }}$ day and concrete with the use of Class 22.5 Portland Cement - on the $11^{\text {th }}$ day. 
The greatest 4-day difference in the gaining of strength is most noticeable when comparing the classes 42.5 and 32.5 , which can significantly affect the timing of construction and restoration of buildings.

It is worth a special note that the quality of prefabricated structures and products is preserved by manufacturing them at a plant. Also, due to the exclusion of labor-intensive and highly skilled work in monolithic construction on the construction site, construction timeframes are shortened.

The use of prefabricated monolithic technology in the construction, restoration of buildings and structures and the use of the method reviewed in this article to calculate construction timeframes, taking into account the influence of various factors such as the use of different cement grades, plasticizers and air temperature will allow building and carrying out reconstruction work in the time required for the speedy restoration and provision of housing for those in need.

\section{References}

1. O.M. Akunina, Foreign experience of state regulation of the reproduction of housing stock // Politics, state and law No. 3. URL: http://politika.snauka.ru/2015/03/2521 (2016).

2. A. A. Lapidus, Efficiency Potential of Organizational and Process-Related Solutions of the Construction Project. Bulletin of Moscow State University of Civil Engineering No. 1. 175-180 (2014).

3. The Government of Western Australia. The Impact of New Building Techniques and Technologies on the Residential Housing Sector of the Construction Industry. Construction Training Fund (2015)

4. I.L. Abramov, T.Y. Poznakhirko, A. Sergeev, The analysis of the functionality of modern systems, methods and scheduling tools, MATEC Web of Conferences 86, 04063 (2016) IPICSE-2016

5. http://www.1c-esk.ru/about/spr/03.html\#osnfakt

6. A.A. Afanasyev, Technology of erection of fully pre-fabricated buildings. M: Publishing house of the Association of Construction Universities, 361 (2012).

7. A.A. Afanasyev, E.P. Matveev, Technologies of reconstruction of residential buildings and buildings. Part I and II. // M., 367 and 363 (2009)

8. V.I. Snarsky, M.M. Aigumov Technology of construction processes. Volume 2. The processes of erection of load-bearing structures (2007)

9. I.G. Sovalov, Ya. G. Mogilevsky, Concrete and reinforced concrete works (1988)

10. Department of the Army. U.S. Army Corps of Engineers. Manual No. 1110-2-3506 Grouting Technology. Washington D.C. (2017).

11. https://world-weather.ru/archive/iraq/summer/

12. SNiP 48.13330.2011 Construction Rules, Construction Organization, (2011)

13. P. P. Oleynik, V. A. Grigoryev, Current Methods of Modeling Standards for Residential Construction Timelines, Constr. Techn. and Org., 42-44 (2014)

14. P. P. Oleynik, V. I. Brodsky, Construction Planning Arrangements. Constr. Techn. and Org., 40-43 (2013)

15. Ammar W. Abbood, Karam M. Al-Obaidi, Achieving energy efficiency through industrialized building system for residential buildings in Iraq. Inter. J. of Sust. Built Envir.. Volume 4, Issue 1, 78-90 (2015).

16. A.A.Lapidus, I.L. Abramov. Calculating a construction company's resource potential as a bidder - Science Bulletin 9-2017-p.6-9. 